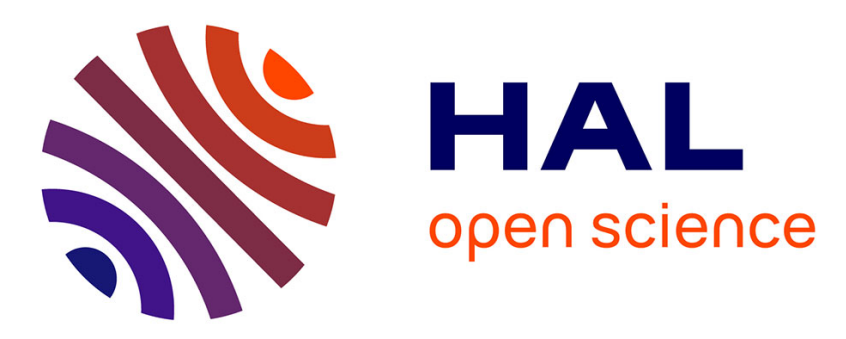

\title{
Prediction of blast wave effects on a developed site
}

Adel M. Benselama, Mame J.-P. William-Louis, François Monnoyer de Galland

\section{To cite this version:}

Adel M. Benselama, Mame J.-P. William-Louis, François Monnoyer de Galland. Prediction of blast wave effects on a developed site. International Journal of Impact Engineering, 2010, 37 (4), pp.385. 10.1016/j.ijimpeng.2009.08.003 . hal-00657573

\section{HAL Id: hal-00657573 https://hal.science/hal-00657573}

Submitted on 7 Jan 2012

HAL is a multi-disciplinary open access archive for the deposit and dissemination of scientific research documents, whether they are published or not. The documents may come from teaching and research institutions in France or abroad, or from public or private research centers.
L'archive ouverte pluridisciplinaire HAL, est destinée au dépôt et à la diffusion de documents scientifiques de niveau recherche, publiés ou non, émanant des établissements d'enseignement et de recherche français ou étrangers, des laboratoires publics ou privés. 


\section{Accepted Manuscript}

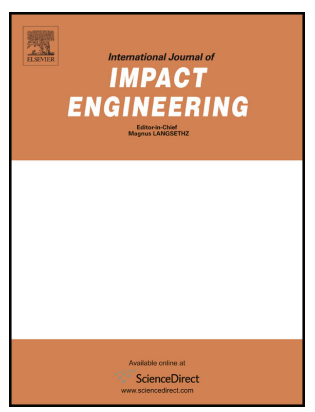

Title: Prediction of blast wave effects on a developed site

Authors: Adel M. Benselama, Mame J.-P. William-Louis, François Monnoyer

PII: S0734-743X(09)00142-0

DOI: $\quad$ 10.1016/j.ijimpeng.2009.08.003

Reference: IE 1821

To appear in: International Journal of Impact Engineering

Received Date: 5 May 2009

Revised Date: 22 July 2009

Accepted Date: 8 August 2009

Please cite this article as: Benselama AM, William-Louis MJ-P, Monnoyer F. Prediction of blast wave effects on a developed site, International Journal of Impact Engineering (2009), doi: 10.1016/ j.ijimpeng.2009.08.003

This is a PDF file of an unedited manuscript that has been accepted for publication. As a service to our customers we are providing this early version of the manuscript. The manuscript will undergo copyediting, typesetting, and review of the resulting proof before it is published in its final form. Please note that during the production process errors may be discovered which could affect the content, and all legal disclaimers that apply to the journal pertain. 


\title{
Prediction of blast wave effects on a developed site
}

\author{
Adel M. Benselama, ${ }^{*, a, b}$, Mame J.-P. William-Louis ${ }^{\mathrm{a}, \mathrm{b}}$, François Monnoyer ${ }^{\mathrm{a}, \mathrm{b}}$ \\ ${ }^{a}$ Univ Lille Nord de France, F-59000 Lille, France \\ ${ }^{b}$ UVHC, LME, F-59313 Valenciennes, France
}

\begin{abstract}
The guidelines for protecting against and mitigating explosion hazards require knowledge and either the experimental or theoretical evaluation of blast wave parameters. To this end, this article proposes a numerical method for simulating blast wave propagation in complex geometries. This method permits an on-the-ground TNT-like explosion and the subsequent blast wave to be simulated, with the possibility of modifying the ground topology by adding a number of obstacles. The numerical model is explored from both a qualitative and quantitative point of view by comparing it to experimental data, with a correct determination of the wave amplitude and phase signature at different key-positions. The pressure and Mach number distributions deduced from simulations in complex congested areas highlight various fluidsolid interactions, such as regular reflections and diffractions. The iso-damage diagrams of different obstacle layouts are also presented and discussed.
\end{abstract}

Key words: Blast loading, Semi-confined environment, Iso-damage diagram, Finite volume method, Cartesian mesh

PACS: 47.40.Rs, 47.11.-j, 62.20.D-

\section{Nomenclature}

\section{Greek Symbols}

$\Delta p \quad$ overpressure, $\Delta p=p-p_{\text {ref }}(\mathrm{Pa})$

$\Delta x \quad$ specific length of the current three-dimensional mesh cell

$\gamma \quad$ heat capacity ratio of the perfect gas

\footnotetext{
${ }^{*}$ Corresponding author. Tel.: +33327511971; Fax: +33327511961. E-mail address: MustaphaAdel.Benselama@univ-valenciennes.fr (A.M. Benselama).
} 
$\lambda \quad$ mesh numerical frequency, $\lambda=M_{c}^{1 / 3} / \Delta x^{3 D}\left(\mathrm{~kg}^{1 / 3} / \mathrm{m}\right)$

$\omega \quad$ constant for Jones-Wilkins-Lee (JWL) equation of state

$\rho \quad \operatorname{density}\left(\mathrm{kg} / \mathrm{m}^{3}\right)$

$\Sigma \quad$ three-dimensional mesh cell surface area $\left(\mathrm{m}^{2}\right)$

$t_{Q} \quad$ pulse loading duration $(s)$

\section{Roman Symbols}

n normal to surface vector

u velocity vector

a speed of sound $(\mathrm{m} / \mathrm{s})$

$A, B, C, R_{1}, R_{2}$ constants for the JWL equation of state

$b \quad$ vector of primitive variables

$c_{f} \quad$ friction coefficient

$d \quad$ distance of the blocks gap in the damage parametric study $(m)$

$E \quad$ total specific internal energy, $E=e+\frac{1}{2}\left(u^{2}+v^{2}+w^{2}\right)(J / k g)$

e specific internal energy $(\mathrm{J} / \mathrm{kg})$

$F \quad$ pulse loading in the SDOF model $\left(N / m^{2}\right)$

$F, G, K$ flux vectors

$H \quad$ total specific enthalpy, $H=E+p / \rho(J / k g)$

$h \quad$ blocks height in the damage parametric study $(m)$

$K \quad$ structural element modulus of elasticity defined in the SDOF model $\left(N / m^{3}\right)$

$L \quad$ one-dimensional domain radius $(m)$

$l \quad$ blocks width in the damage parametric study $(m)$

$M \quad$ specific surface mass defined in the SDOF model $\left(\mathrm{kg} / \mathrm{m}^{2}\right)$

$M_{c} \quad$ explosive charge mass $(\mathrm{kg})$

$p \quad$ pressure $(\mathrm{Pa})$

$Q \quad$ pressure (pulse) history used in the SDOF model $(P a)$

$R \quad$ structural element resistance function defined in the SDOF model $\left(N / m^{2}\right)$

$S \quad$ vector of source terms

$t \quad$ time $(s)$

$U \quad$ vector of conservative variables 
$u, v, w$ velocity components $(\mathrm{m} / \mathrm{s})$

$V \quad$ three-dimensional mesh cell volume $\left(\mathrm{m}^{3}\right)$

\section{Superscripts}

* mesh cell face extrapolation

$3 D$ three-dimensional mesh

\section{Subscripts}

$\delta \quad$ structural element

$c$ explosive charge

ref reference conditions

wall solid walls boundaries

\section{Introduction}

Explosion hazard modeling is a challenging problem since it involves several physical, often complex, interacting aspects. In combustion explosions, the available quantity of energy changes rapidly and is constantly redistributed among heat, the kinetic and chemical energy forms $[1,2]$. The problem becomes even more complex when the subsequent blast wave propagation is assumed to interact with the nearby structures. Structural damage is mainly due to the incident blast wave, but the successive reflections also have a significant effect in congested areas. In confined or semi-confined areas, damage is more likely to happen far from the detonation source since high velocity fragments are assumed to be projected outward [3]. Obstructions and blast waves interact closely since the blast wave impulses affect the structures and may cause failures, while the structures in turn modify the blast wave's propagation patterns.

For the above reasons, it is important to have a profound understanding of exactly what kind and what levels of blast loading take place when a shock wave propagates from a blast in a terrain obstructed by building. Some approximate and empirical formulae have already been derived to predict the maximum pressure and the effect of the impulse on structures for both open and congested terrains [4]. However, when they are not impossible due to safety and environmental considerations, explosion tests are still expensive and awkward to set up. With the development of computing power and 
the increasing sophistication of computational methods, it has become possible to use numerical techniques to predict blast loading and blast effects on structures [5]. The blast wave simulation techniques already have achieved a relative degree of success, although they still have a ways to go in order to attain a satisfactory level of maturation in terms of dependability, accuracy and reliability at a reasonable numerical cost. In fact the simulations performed by Zhou et al. [4], Ambrosini et al. [6] and Sklavounos et al. [7], for instance, show that -because of both hardware and software capacityreducing the mesh size in order to improve the solution estimation was not possible.

This study proposes an accurate and an inexpensive numerical method that permits the interaction of the blast wave and the structure to be estimated in congested areas. This study also examines the risk assessment and consequence models that are used to approximate the hazard posed by blast. The simulation method performs an initial computation of the area around the explosion by considering the spherical symmetry of the propagating blast wave to a sufficiently advanced stage [8]. Then, using an appropriate remapping technique, the spherical symmetry solution is transferred onto the three-dimensional mesh in order to continue the simulation for the effective geometry, which can generally be more complex.

Historically, blast analysis has involved either simplified analytical methods or the use of supercomputers for detailed multi-factor numerical simulations. However, the first case produces results that are too approximate, which can be problematic given the complexity of blast analysis. In the second case, a complete direct discretization of the analyzed structures may lead at best to simulations that are time and/or cost prohibitive and, at worst, to computer memory overflow if conventional computers are used for the calculations. Alternatively, using iso-damage diagrams, which have been widely discussed in the literature $[9,10]$, looks to be a more attractive and practical way to correlate pressure and impulse to the damage produced in the various parts of the structures. In this study, the theoretical single-degreeof-freedom approach was used because of its high level of confidence, instead of the original iso-damage pressure-impulse diagrams $[6,11]$.

In this paper, the numerical method used to describe the blast wave propagation in a congested environment is presented first. This method is based on the finite volume method applied to Cartesian meshes. A congested area is considered in which a series of solid blocks, representing urban structures, is located next to the explosive charge. In order to assess the effects of the ex- 
plosion on the structures, it is necessary to evaluate the pressure and impulse distributions accurately and reliably. The accuracy is therefore controlled at certain positions, for which experimental data are available [12]. Evaluated using the single-degree-of-freedom approach, a parametric analysis of the damage of diverse structure configurations is also included and discussed.

\section{Physical and numerical models}

\subsection{The transport model}

The dynamic and thermal behavior of the propagation phenomena is governed by the unsteady transport equations for mass, momentum and energy. Viscous and thermal diffusion processes may play a significant role in the overall transport phenomena, but they are not included in the conventional diffusion terms leading to the Navier-Stokes equations, as this would require very fine spatial discretization in the regions with strong velocity and temperature gradients. The corresponding grid scales would be extremely small and thus would involve mesh sizes beyond the capacity of the computers currently available. Consequently, the effects of viscous and thermal diffusion are implemented as global source terms added to the transport equations.

\subsubsection{The three-dimensional Euler equations}

In this case, the Euler transport equations are expressed:

$$
\frac{\partial U}{\partial t}+\frac{\partial F(U)}{\partial x}+\frac{\partial G(U)}{\partial y}+\frac{\partial K(U)}{\partial z}=S(U)
$$

where $t$ is the time, $U$ is the variables vector, and $F(U), G(U)$ and $K(U)$ are the fluxes in $-x,-y$ and $-z$ directions, respectively. This vector and these fluxes are defined as:

$$
\begin{gathered}
U=\left(\begin{array}{c}
\rho \\
\rho u \\
\rho v \\
\rho w \\
\rho E
\end{array}\right), \quad F(U)=\left(\begin{array}{c}
\rho u \\
\rho u^{2}+p \\
\rho u v \\
\rho u w \\
\rho u H
\end{array}\right), \\
G(U)=\left(\begin{array}{c}
\rho v \\
\rho u v \\
\rho v^{2}+p \\
\rho v w \\
\rho v H
\end{array}\right), \quad K(U)=\left(\begin{array}{c}
\rho w \\
\rho u w \\
\rho v w \\
\rho w^{2}+p \\
\rho w H
\end{array}\right) .
\end{gathered}
$$


$S$ is the source term vector that includes the viscous and thermal diffusion energy terms:

$$
S(U)=\left(S_{\rho}, \mathbf{S}_{\mathbf{q}}{ }^{T}, S_{\rho h}\right)^{T} ; \mathbf{S}_{\mathbf{q}}=\left(S_{\rho u}, S_{\rho v}, S_{\rho w}\right)^{T} .
$$

where $S_{\rho}, S_{\rho u}, S_{\rho v}, S_{\rho w}, S_{\rho h}$ are, respectively, the mass, the x-, y- and $\mathrm{z}$-momentum, and the energy source terms.

At this stage, both air and the expanded detonation gases are assumed to obey the perfect gas law, expressed in equation (5):

$$
p=(\gamma-1) \rho e .
$$

The system of equations (1) and (5) is completed by the boundary conditions and the initial conditions, as described below.

\subsubsection{The numerical method}

The unsteady Euler three-dimensional problem (1) is solved by a software developed in-house [13]. The numerical method involves an unstructured finite-volume cell-centered approach that couples the classic second-order upwind scheme with the two-step van Leer time-explicit integration scheme [14]. This coupling yields a second-order accurate-in-space-and-time method. In order to prevent the numerical oscillations that can occur in regions with strong gradients, the minmod limiter is used [14].

The space discretization is performed by an automatic Cartesian grid generator, which takes the exact model geometry into account [15]. In order to avoid contiguous cells with a too-small volume ratio, the smooth octree structure and merging processes are also included [13].

In addition, the Courant-Friedrichs-Lewy (CFL) condition must be satisfied in order to guarantee the stability of the numerical method. To construct the CFL for the three-dimensional case, the space step is defined by the ratio of the cell volume $V$ to half of its surface area $\Sigma$. This can be expressed as:

$$
\Delta t=C F L \times \min \left(\frac{\Delta x^{3 D}}{(\|\mathbf{u}\|+a)}\right), \quad \Delta x^{3 D}=\frac{2 V}{\Sigma} .
$$

The value of $C F L=0.9$ was found to be the maximum to insure the stability of the computational scheme for the cases tested during the current simulations.

Initially, the flow is assumed to be at rest in all the three-dimensional domain, except inside the sphere of radius $L$ that contains and centered 
on the explosive charge. In this sphere, the flow is disturbed by the blast wave calculated using a one-dimensional spherical procedure that is made compatible with the three-dimensional mesh thanks to the 1D-3D remapping algorithm described in the following sub-section.

\subsubsection{Initial conditions and the remapping algorithm}

When simulating blast waves, the mesh cell size $\Delta x^{3 D}$ must be at least one order of magnitude smaller than the typical local blast wavelength in order to correctly resolve the blast wave. After the detonation onset, the blast wave trace is still very sharp, and the corresponding wavelength is of the order of the explosive radius length. Assuming that the explosive charge is spherical, the space resolution condition to be satisfied is:

$$
\Delta x^{3 D} \leq \frac{1}{10} \frac{\sqrt[3]{M_{c}}}{\sqrt[3]{\frac{4 \pi}{3} \rho_{c}}}
$$

As suggested by Catlin et al. [12], relation (7) may be expressed using the mesh frequency $\lambda$ (where for TNT, $\rho_{c} \approx 1600 \mathrm{~kg} / \mathrm{m}^{3}$ ):

$$
\lambda=\frac{M_{c}^{1 / 3}}{\Delta x^{3 D}} \gtrsim 100
$$

At the detonation onset, however, an equivalent but more restrictive condition must be applied and, from two different but related points, may potentially make an accurate computation infeasible in terms of three-dimensional geometries. First, finely discretizing the three-dimensional domain implies a huge mesh, so much so that conventional computer resources, especially memory resources, would hardly be sufficient to handle the calculation. Second, according to relation (6), the combination of a small mesh cell size and the high velocity involved at the blast onset gives rise to extremely small time steps, and consequently the computation time would be unreasonably long. In either case, accurate simulation would be practically unaffordable.

One way to overcome this problem is to solve the blast onset in a simplified manner, when applicable. It is actually possible to consider the wave as propagating isotropically at the onset of the explosion. This spherical one-dimensional approach has proven to be valid as long as the blast wave propagates in an open area $[3,16]$. In this case, the simplified approach represents a good alternative to fully three-dimensional approaches. Clearly, the 
problem of an explosive charge detonating very close to the obstacles does not belong to the freely propagating wave class of problems. However, with certain considerations, the spherical treatment may be extended beyond this limitation, as explained below.

If the ground or solid walls act as perfect and rigid planes when the explosion occurs on their surface, then the blast wave would be reflected back with no energy loss, and the energy driving the wave would be doubled. This may be seen as the blast wave generated by a half sphere detonating on the ground with the same mass of the original explosive charge, as illustrated by Figure (1). If the ground or solid walls dissipate some of the energy, for instance by cratering or in-structure shocks, the relatively correct rule of multiplying the explosive mass by a factor of 1.8 may be used [3]. All explosive shape specificities and the effects of ground irregularities are usually localized, so much so that the blast wave is quickly smoothed out behind them. Hence, the spherical model may still be used in the truncated physical domain. The spherical part representing the ground, which is not of interest here, is simply ignored during the process of remapping the one-dimensional solution onto the three-dimensional domain. Outside the remapped region, the flow is assumed to be at rest.

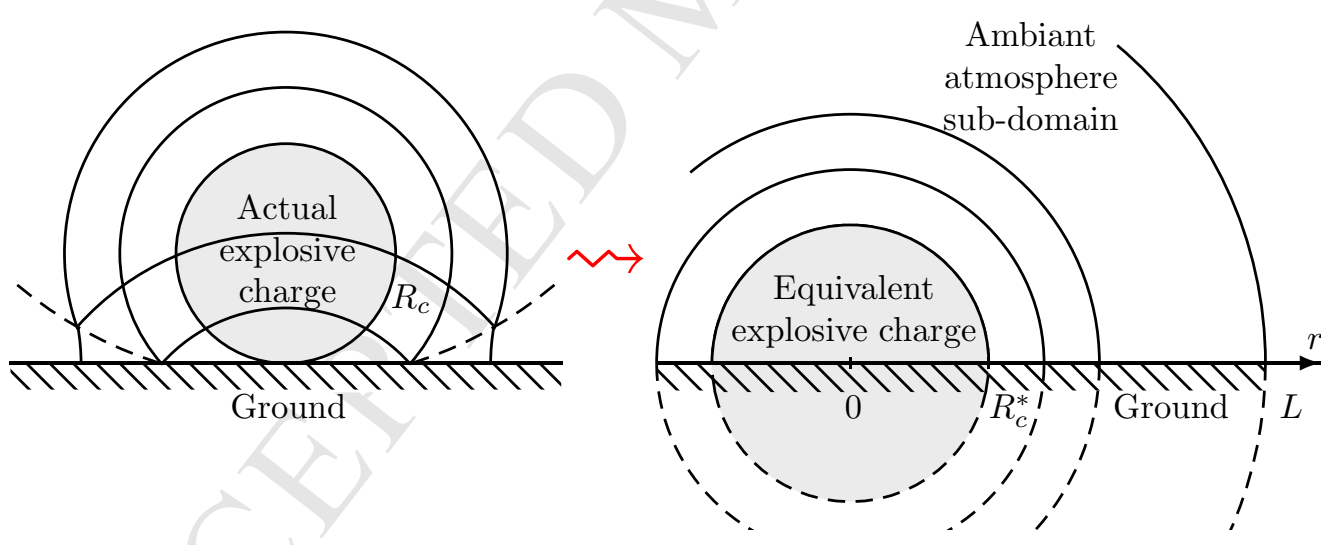

Figure 1: Illustration of the actual explosion onset and the equivalent spherical onedimensional model. $R_{c}^{*}=\sqrt[3]{\alpha} R_{c}$, where $1.8 \leq \alpha \leq 2$.

In contrast with the more advanced stages of the explosion, at this stage of the explosion, it would not be appropriate to describe the state of the hot detonation gases using the perfect gas law. Instead, the one-dimensional spherical problem is solved by considering that the hot detonation gases obey 
the Jones-Wilkins-Lee (JWL) law, which reads:

$$
\begin{aligned}
p= & A\left(1-\frac{\omega}{R_{1}} \frac{\rho}{\rho_{c}}\right) \exp \left(-R_{1} \rho_{c} / \rho\right) \\
& +B\left(1-\frac{\omega}{R_{2}} \frac{\rho}{\rho_{c}}\right) \exp \left(-R_{2} \rho_{c} / \rho\right)+\omega \rho e .
\end{aligned}
$$

where the constants $A, B, R_{1}, R_{2}, \omega$ and $\rho_{c}$ depend on the explosive material and are given in due course.

The spatially-derived remapping technique, which extrudes the spherical one-dimensional solution to the three-dimensional mesh, has already been described in detail in the authors' previous publications [8, 17]. For this reason, the detailed description is not given here.

\subsubsection{Boundary conditions}

The boundary conditions considered in this paper are:

- Pseudo no-slip condition at the solid boundaries This is a slip condition with additional friction source terms. These boundaries are termed solid walls, where the flow variables satisfy:

$$
\begin{aligned}
& \left.p^{*}\right|_{\text {Wall }}=p \\
& \left.\mathbf{u}^{*}\right|_{\text {Wall }} \cdot \mathbf{n}=0, \\
& \left.\mathbf{S}_{\mathbf{q}}\right|_{\text {Wall }}=-\left.\frac{1}{2}\left(\rho c_{f} \frac{\Sigma_{\text {Wall }}}{V}\left\|\left.\mathbf{v}\right|_{\text {Wall }}\right\|\right) \mathbf{v}\right|_{\text {Wall }}, \\
& \left.S_{\rho h}\right|_{\text {Wall }}=\left.\left.\mathbf{S}_{\mathbf{q}}\right|_{\text {Wall }} \cdot \mathbf{v}\right|_{\text {Wall }},
\end{aligned}
$$

where $\mathbf{v}=\mathbf{u}-(\mathbf{u} \cdot \mathbf{n}) \mathbf{n} ; \mathbf{u}$ and $p$ are, respectively, the velocity vector and pressure at the cell center; $\mathbf{u}^{*}$ and $p^{*}$ are, respectively, the velocity and pressure extrapolations at the cell surface that belongs to the wall boundary. The condition (11) insures the impenetrability of the wall boundaries, while the source terms (12) and (13), introduced respectively in the momentum and energy equations, approximate the no-slip condition. This approximation becomes exact for a steady flow if the friction coefficient $c_{f}$ is set correctly. More accurate, but also more complicated, formulae can be used instead of (12) to take the unsteadiness of the flow into account, but are not considered in this paper. For the sake of simplicity, the friction coefficient is assumed to 
be constant and is set to 0.008 , which is a mean value for moderately rough concrete surfaces. The relation (10) is a first-order extrapolation of the pressure to insure the closure of the numerical problem from the characteristic point of view.

- Non-reflecting condition at the far field boundaries This condition is based on the second-order extrapolation of the flow's primitive variables (i.e., density, velocity and pressure) from the numerical domain to the far field boundaries:

$$
b^{*}=b+\Delta \mathbf{x} \cdot \nabla b,
$$

where $\Delta \mathbf{x}$ is the vector that links the cell center and the center of its considered surface. The conservative variables (e.g., momentum and enthalpy) are deduced from this extrapolation of the primitive variables.

\subsection{Pressure-Impulse diagrams for the single-degree-of-freedom model}

The Pressure-Impulse (P-I) diagram method is a convenient method for evaluating the structural safety in terms of the impact load. To correlate the pressures and impulses to the damage levels experienced, the single-degreeof-freedom (SDOF) model can be used [9]. The structural element -either cantilevered or fixed at both ends- is modeled by a simple mass-and-spring system that reacts to the blast load. In this model, the safety of this system -and thus that of the structural element- is characterized by its maximum displacement. The failure region is usually located mid-span in the structural elements due to excessive bending deformation.

The momentum equation describing the mass displacement in an elasticplastic SDOF structural model can be expressed as:

$$
M \ddot{y}_{\delta}+R\left(y_{\delta}\right)=Q(t) .
$$

where $y_{\delta}$ is the element deflection from the initial equilibrium position. The dot and double dot over the variables represent the first and second time derivative, respectively.

The initial conditions are:

$$
\left\{\begin{array}{l}
y_{\delta}(t=0)=0 \\
\dot{y}_{\delta}(t=0)=0
\end{array}\right.
$$


The resistance function of an elastic-perfectly plastic spring is used:

$$
\begin{cases}\dot{R}=K \dot{y}_{\delta} & \text { for }\left(\|R\|<R_{0}\right) \text { or }\left(\|R\|<R_{0} \text { and } R \dot{y}_{\delta}<0\right) \\ \dot{R}=0 & \text { for }\left(\|R\|=R_{0}\right) \text { and }\left(R \dot{y}_{\delta} \geqslant 0\right)\end{cases}
$$

where $R_{0}$ corresponds to the spring's limit of elasticity. Figure (2) shows this spring's hysteresis loop for a periodic pulse. (yelast is the spring's deflection that corresponds to its limit of elasticity.)

Using the pulse peak $Q_{m}$ and the maximum displacement $y_{c}$, two nondimensional parameters are defined, namely:

$$
q_{m}=\frac{Q_{m}}{R_{0}}
$$

and

$$
\alpha=\frac{R_{0}}{K y_{c}} .
$$

The parameter $\alpha$ represents the damage level of the structural element. The smaller $\alpha$, the higher the level of damage.

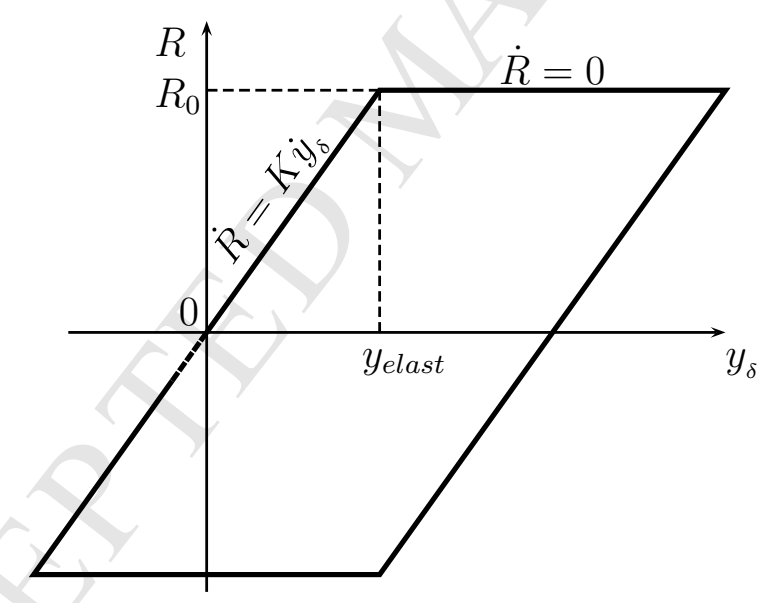

Figure 2: Illustration of the elastic, perfectly plastic spring resistance function.

In the case of a rigid-perfectly plastic response of the element (i.e., $\alpha<$ 1 and $q_{m} \gg 1$ ), solving the ordinary differential system (15-16) gives the following iso-damage curves equation [10]:

$$
\frac{1}{p_{e}}+\frac{2}{i_{e}^{2}}=\frac{1}{\alpha}
$$


whatever the pulse function shape is, provided that $i_{e}$ and $p_{e}$ are expressed as follows:

$$
\begin{gathered}
i_{e}=q_{m} \alpha \int_{0}^{\tau_{Q}} q(\tau) d \tau, \\
p_{e}=\frac{i_{e}}{2 \tau_{\text {mean }}}
\end{gathered}
$$

where

$$
\begin{gathered}
\tau_{\text {mean }}=\frac{q_{m} \alpha}{i_{e}} \int_{0}^{\tau_{Q}} \tau q(\tau) d \tau \\
\tau=\frac{t}{\sqrt{M / K}} \\
q(\tau)=\frac{Q(\tau)}{Q_{m}}
\end{gathered}
$$

and

$$
\tau_{Q}=\frac{t_{Q}}{\sqrt{M / K}}
$$

In the damage diagram section, relation (20) is used to determine the potential damage caused by the blast wave at the congested site.

\subsection{The simulated configuration}

For this study, an explosion at the ground level was simulated, and the results of the simulation compared to experimental data provided from a series of field-scale tests performed by the Health and Safety Laboratory at Buxton, Derbyshire (UK) in 2001 [12]. The purpose of the field-scale tests was to study the sheltering effects of solid obstacles in connection to a blast wave generated by the detonation of high-power explosives. The ambiant pressure was $p_{\text {ref }}=101325 \mathrm{~Pa}$. The obstacles in the trials were identical equidistant concrete blocks of square cross-section, and the exploding material was $320 \mathrm{~g}$ of the PE4 plastic explosive with a TNT equivalence of approximately 1.3. (The characteristics of the PE4 explosive are summarized in Table 1.) The explosive was formed into a hemisphere and detonated remotely using a detonator inserted into the top of the explosive. The pressure time histories were obtained using five piezo-electric gauges located among the obstacles along or offset from the plane of symmetry. Figure (3) shows the dimensions of the experimental set-up: $L_{1}=1.7 \mathrm{~m}, L_{2}=L_{3}=1.2 \mathrm{~m}, A=H=0.6 \mathrm{~m}$ and $B=8.5 \mathrm{~m}$. The gauges were placed so that $L_{4}=3.9 \mathrm{~m}, L_{5}=1.8 \mathrm{~m}$ and 


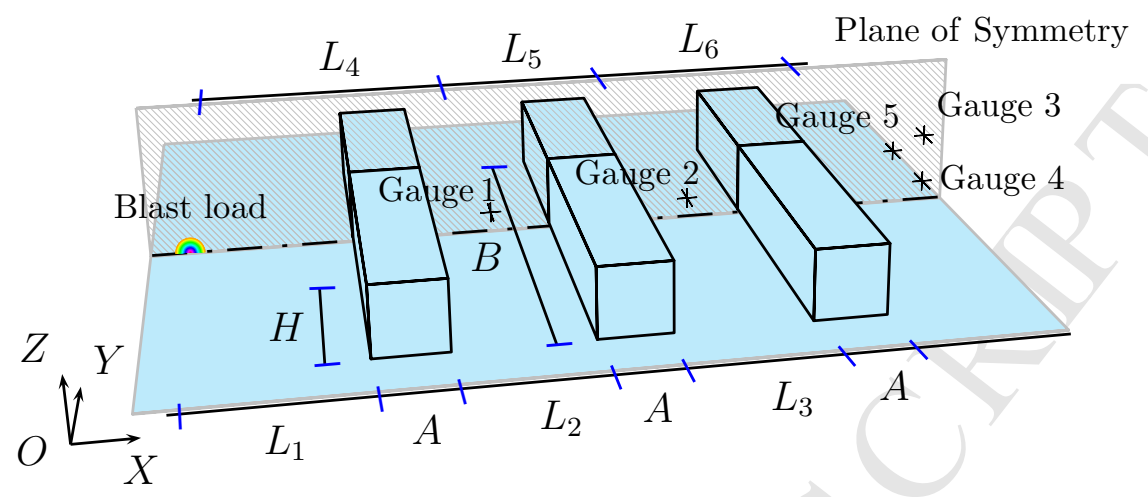

Figure 3: Illustration of the experimental set-up for the on-the-ground explosion test.

$L_{6}=3.0 \mathrm{~m}$. The gauges 1,2 and 4 were positioned $0.3 \mathrm{~m}$ above the ground along the plane of symmetry, the gauge 3 was positioned $0.9 \mathrm{~m}$ off the ground along the plane of symmetry, and the gauge 5 was positioned $0.3 \mathrm{~m}$ off the ground and with a $2.125 \mathrm{~m}$ offset.

Table 1: Parameters values used in the JWL law for describing PE4 explosive hot gases

\begin{tabular}{|c|c|c|c|c|c|c|c|c|}
\hline $\begin{array}{l}\text { Specific } \\
\text { energy, } \\
e_{c}\end{array}$ & Density, $\rho_{\mathbf{c}}$ & $\begin{array}{l}\text { Deto- } \\
\text { nation } \\
\text { speed, } \\
u_{c}\end{array}$ & $\begin{array}{l}\text { Deto- } \\
\text { nation } \\
\text { pressure, } \\
p_{C J}\end{array}$ & $A$ & $B$ & $R_{1}$ & $R_{2}$ & $\omega$ \\
\hline$k J / k g$ & $10^{3} \times \mathrm{kg} / \mathrm{m}^{3}$ & $\mathrm{~km} / \mathrm{s}$ & $G P a$ & $10^{11} \mathrm{~Pa}$ & $10^{9} \mathrm{~Pa}$ & - & - & - \\
\hline 5876 & 1.56 & 8.50 & 6.2 & 3.48 & 11.3 & 7.0 & 2.0 & 0.24 \\
\hline
\end{tabular}

\section{Results and discussion}

The numerical simulation is validated by comparing it to experimental data for the site positions presented in the last section. Then, the iso-damage diagrams for the various structures are created using the SDOF approach.

The numerical domain was divided into about 1.4 million cells. The explosive charge region was specifically refined $(\lambda=96$, which corresponds 
in this case to $\Delta x^{3 D}=7.7 \mathrm{~mm}$ ) in order to meet the remapping condition (8) needed to extrude the one-dimensional solution onto the three-dimensional mesh. Away from the explosive charge and the obstacles region, the mesh was coarser as illustrated by Figure (4). A $2.4 G H z$ AMD64 ${ }^{\circledR} 2 G B$ machine was able to complete $30 \mathrm{~ms}$ of simulation time in about $210 \mathrm{~h}$.

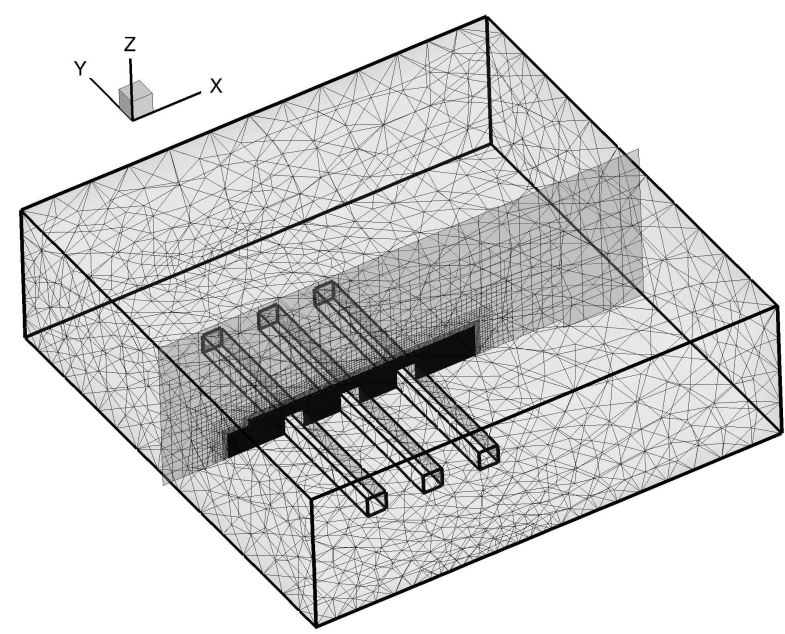

Figure 4: Illustration of the mesh at the domain's surface and symmetry cross-section.

\subsection{Validation of the numerical method}

Figures (5), (6), (7), (8) and (9) present the overpressure history $\Delta p$ at gauges $1,2,3,4$ and 5 , respectively, produced by the numerical simulation compared to the data recorded during the experiments [12]. The simulated overpressure histories conform to the experimental data in terms of both pressure magnitude and phase. In particular, the simulated arrival times are correct. Even though they are supposed to be behind concrete blocks, the pressure signature for gauges 1 and 2 show many shocks of the same order of magnitude due to reflected waves from the canyon between to successive block of concrete. In addition, because no block exists downstream of gauge 3 , no significant reflection is recorded except the ground effect, and this effect is much more significant on gauges 4 and 5 than on gauge 3 , since the gauge 3 was located $0.6 \mathrm{~m}$ higher than gauges 4 and 5 .

The maximum positive (resp. negative) overpressure magnitudes, the arrival times, the phase durations and impulses are given in Tables 2-7. Since 


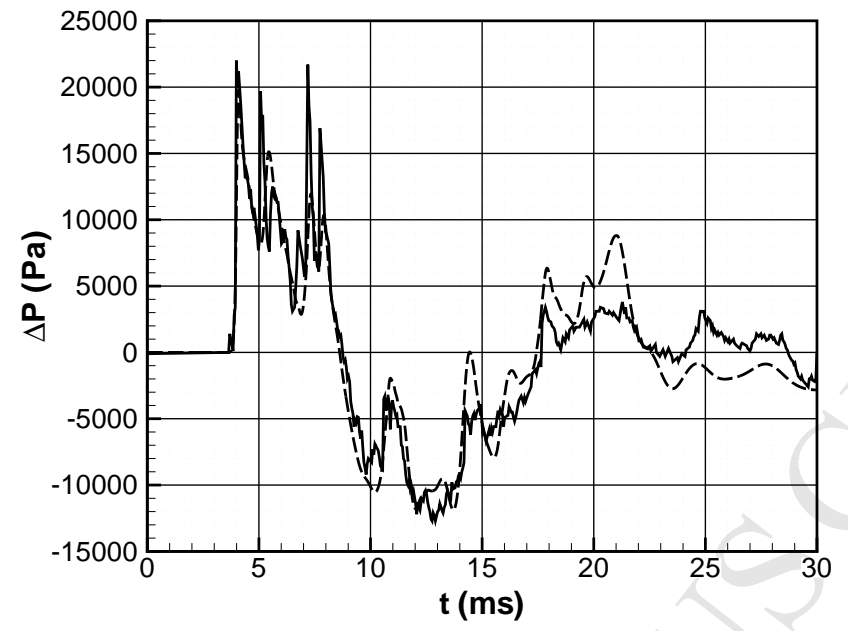

Figure 5: Overpressure time history at gauge 1 ( - - numerical data, - experimental data $[12])$.

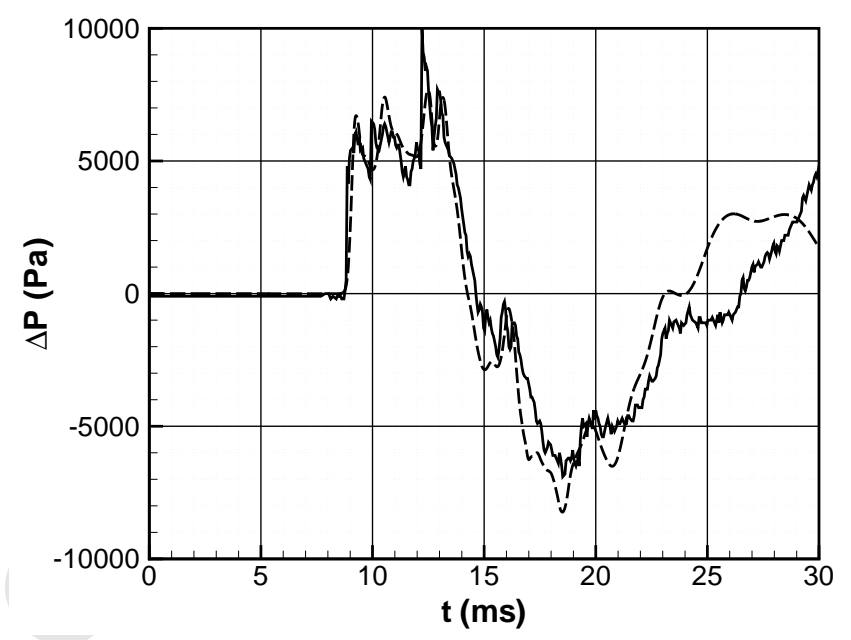

Figure 6: Overpressure time history at gauge 2 (- - numerical data, - experimental data $[12])$. 


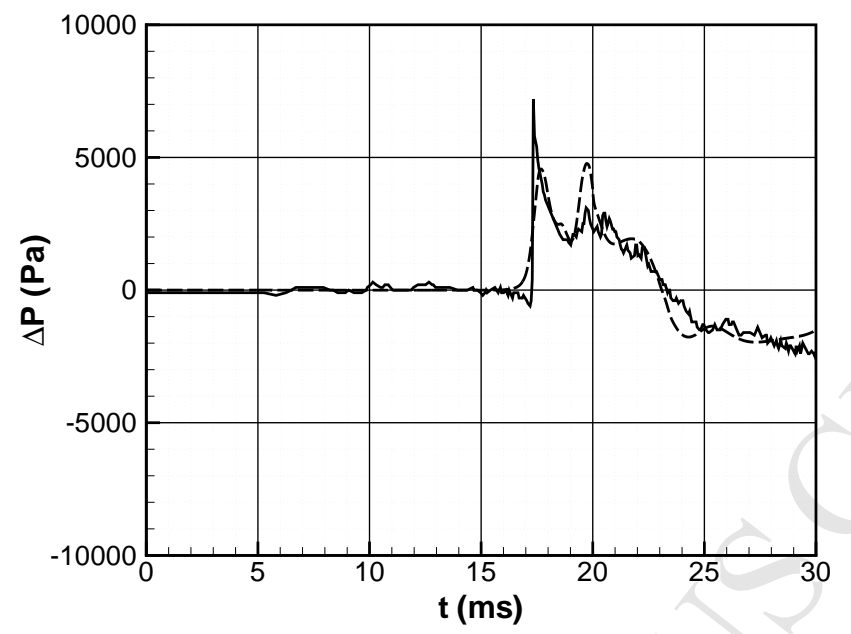

Figure 7: Overpressure time history at gauge 3 (- - numerical data, - experimental data $[12])$.

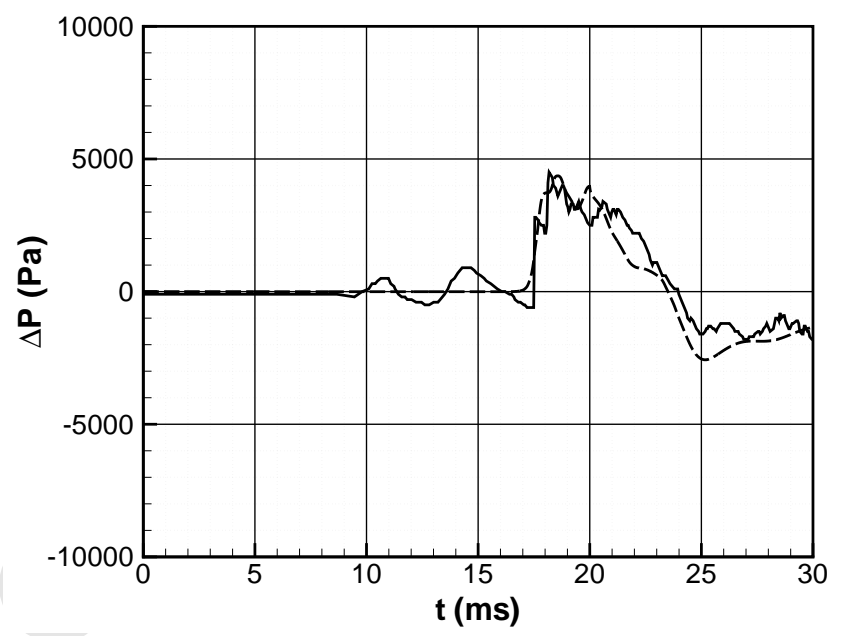

Figure 8: Overpressure time history at gauge 4 (- - numerical data, - experimental data $[12])$. 


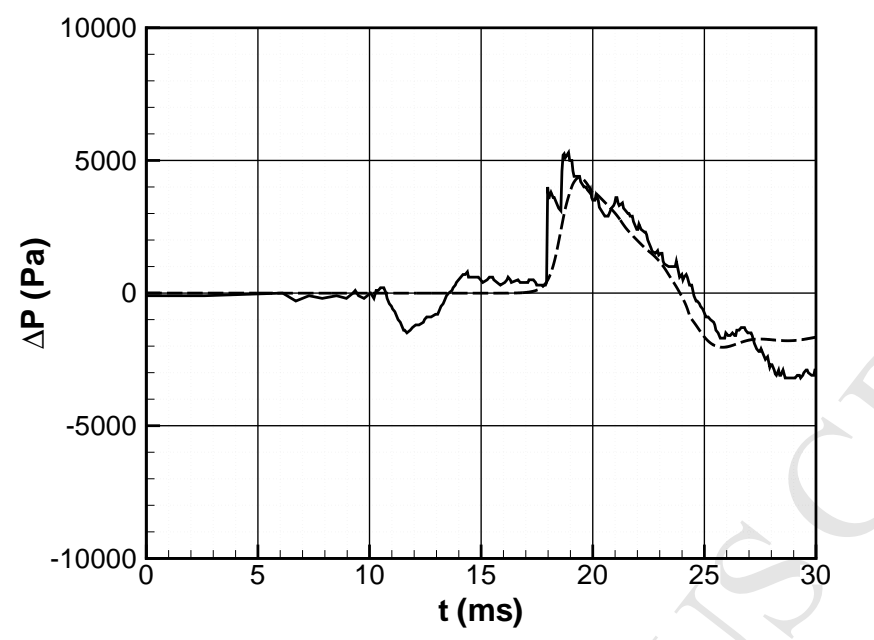

Figure 9: Overpressure time history at gauge 5 (- - numerical data, - experimental data [12]).

the experimental recordings were performed only up to $30 \mathrm{~ms}$, information about the negative phase duration and impulse was not available for gauges 3,4 and 5. As can be seen in these tables, the error in the predictions of the maximum overpressure magnitude never exceeds $40 \%$ and is rather local, since the impulse errors are less than $8 \%$. Arrival times are difficult to determine, especially when the numerical solution changes smoothly. For this reason, a threshold, set to $10 \%$, related to the maximum peak was used instead of the initial change in the pressure signal. According to Table 4, arrival times were accurately predicted by the numerical simulation, since the error for all gauges is, at worst, $2.7 \%$. In addition, both the positive and negative phase durations were satisfactorily predicted, while the impulses were very accurately predicted.

Figures (10) and (11) present the distribution of the Mach number and the relative overpressure on the ground and on the concrete blocks for a simulation time varying from $1 \mathrm{~ms}$ to $25 \mathrm{~ms}$. At the blast onset, a rarefaction happens in the explosive charge volume, because of the rapid fluid expansion [16]. This rarefaction is followed by an inbound compression wave propagating from the hot gases/air contact surface. Due to the sphericity pattern of this propagation phenomenon, the inbound shock overpressure increases 
Table 2: Relative error between the experimental and computed positive peak overpressures

\begin{tabular}{llll}
\hline Gauge & $\begin{array}{l}\text { Experimental } \\
\text { value }(k P a)\end{array}$ & $\begin{array}{l}\text { Computational } \\
\text { value }(k P a)\end{array}$ & $\begin{array}{l}\text { Relative } \\
\text { error }(\%)\end{array}$ \\
\hline Gauge 1 & 21.2 & 19.75 & -6.84 \\
Gauge 2 & 10.0 & 7.60 & -24.00 \\
Gauge 3 & 7.8 & 4.56 & -41.53 \\
Gauge 4 & 5.0 & 4.35 & -13.00 \\
Gauge 5 & 5.1 & 4.34 & -14.90 \\
\hline
\end{tabular}

Table 3: Relative error between the experimental and computed negative peak overpressures

\begin{tabular}{llll}
\hline Gauge & $\begin{array}{l}\text { Experimental } \\
\text { value }(k P a)\end{array}$ & $\begin{array}{l}\text { Numerical } \\
\text { value }(k P a)\end{array}$ & $\begin{array}{l}\text { Relative } \\
\text { error }(\%)\end{array}$ \\
\hline Gauge 1 & -12.7 & -11.90 & 6.29 \\
Gauge 2 & -6.7 & -8.17 & -21.94 \\
Gauge 3 & -2.4 & -1.97 & -17.91 \\
Gauge 4 & -2.5 & -2.56 & -2.40 \\
Gauge 5 & -3.2 & -2.05 & 35.93 \\
\hline
\end{tabular}

Table 4: Relative error between the experimental and computed arrival times

\begin{tabular}{llll}
\hline Gauge & $\begin{array}{l}\text { Experimental } \\
\text { value }(\mathrm{ms})\end{array}$ & $\begin{array}{l}\text { Numerical } \\
\text { value }(\mathrm{ms})\end{array}$ & $\begin{array}{l}\text { Relative } \\
\text { error }(\%)\end{array}$ \\
\hline Gauge 1 & 3.8 & 3.90 & 2.63 \\
Gauge 2 & 8.8 & 8.86 & 0.68 \\
Gauge 3 & 17.3 & 16.89 & -2.36 \\
Gauge 4 & 17.4 & 17.30 & -0.57 \\
Gauge 5 & 18.0 & 17.94 & -0.33 \\
\hline
\end{tabular}

as the wave approaches the explosion charge center, hence the high level of pressure near the explosive charge center shown on Figure (11a). Due to its intrinsic symmetry, the inbound wave is reflected back and propagates outward when it reaches the explosive charge center. Because of the obstacle geometry and the flow unsteadiness, when the flow is supersonic, it is simul- 
Table 5: Relative error between the experimental and computed positive phase duration

\begin{tabular}{llll}
\hline Gauge & $\begin{array}{l}\text { Experimental } \\
\text { value }(\mathrm{ms})\end{array}$ & $\begin{array}{l}\text { Numerical } \\
\text { value }(\mathrm{ms})\end{array}$ & $\begin{array}{l}\text { Relative } \\
\text { error }(\%)\end{array}$ \\
\hline Gauge 1 & 5.2 & 4.66 & -10.38 \\
Gauge 2 & 6.0 & 5.42 & -9.66 \\
Gauge 3 & 6.4 & 6.02 & -5.93 \\
Gauge 4 & 6.6 & 6.38 & -3.33 \\
Gauge 5 & 6.6 & 5.97 & -9.54 \\
\hline
\end{tabular}

Table 6: Relative error between the experimental and computed negative phase duration

\begin{tabular}{llll}
\hline Gauge & $\begin{array}{l}\text { Experimental } \\
\text { value }(\mathrm{ms})\end{array}$ & $\begin{array}{l}\text { Numerical } \\
\text { value }(\mathrm{ms})\end{array}$ & $\begin{array}{l}\text { Relative } \\
\text { error }(\%)\end{array}$ \\
\hline Gauge 1 & 8.9 & 8.86 & -0.45 \\
Gauge 2 & 11.8 & 8.94 & -24.23 \\
Gauge 3 & $\mathrm{~N} / \mathrm{A}$ & - & - \\
Gauge 4 & $\mathrm{~N} / \mathrm{A}$ & - & - \\
Gauge 5 & $\mathrm{~N} / \mathrm{A}$ & - & - \\
\hline
\end{tabular}

Table 7: Relative error between the experimental and computed positive impulse

\begin{tabular}{llll}
\hline Gauge & $\begin{array}{l}\text { Experimental } \\
\text { value }(P a s)\end{array}$ & $\begin{array}{l}\text { Numerical } \\
\text { value }(P a s)\end{array}$ & $\begin{array}{l}\text { Relative } \\
\text { error }(\%)\end{array}$ \\
\hline Gauge 1 & 45.9 & 43.11 & -6.07 \\
Gauge 2 & 29.4 & 28.86 & -1.83 \\
Gauge 3 & 14.2 & 14.74 & 1.90 \\
Gauge 4 & 15.88 & 14.75 & -7.11 \\
Gauge 5 & 16.28 & 14.99 & -8.10 \\
\hline
\end{tabular}

taneously compressed and slowed down at the concave corners, generating a compression wave that propagates behind the main blast wave and causes flow acceleration and pressure decreasing at the sharp corners, as PrandtlMeyer expansion occurs. This new expansion wave propagates just behind the main blast wave as well. As mentioned by Sklavounos [7], the blast wave is practically preserved over the front facade of each obstacle. The blast 
Table 8: Relative error between the experimental and computed negative impulse

\begin{tabular}{llll}
\hline Gauge & $\begin{array}{l}\text { Experimental } \\
\text { value }(\text { Pas })\end{array}$ & $\begin{array}{l}\text { Numerical } \\
\text { value }(\text { Pas })\end{array}$ & $\begin{array}{l}\text { Relative } \\
\text { error }(\%)\end{array}$ \\
\hline Gauge 1 & -59.28 & -55.80 & 5.87 \\
Gauge 2 & -36.55 & -37.82 & -3.47 \\
Gauge 3 & N/A & - & - \\
Gauge 4 & N/A & - & - \\
Gauge 5 & N/A & - & - \\
\hline
\end{tabular}

waves bypass the obstacles on the side, as well as on the top, because of the obstacles' finite span-wise length. The pressure impulse is thus stronger in the region behind the obstacle ends than in the region near the plane of symmetry, even though this plane is closer to the blast center than the obstacle ends.

The numerical method presented in this paper has proven to have a high degree of confidence and thus was used to predict the damage level of the structures.

\subsection{The damage parametric analysis}

In order to study the sheltering effect related to the site parameters, six obstacle layouts are simulated following the method presented in section (2) with the same mass of PE4 explosive, namely $M_{c}=320 \mathrm{~g}$. The geometric configurations of these layouts are depicted in Figure (12) and the parameters, corresponding to the blocks height $h$, width $l$ and gap width $d$, defining each scenario are given in Table 9. Although different parameter ratios are used, the geometric configurations are taken so that the first-obstaclefront-facade, the mid-gap-plane and the second-obstacle-rear-facade remain at equal distance from the explosive charge as illustrated by Figure (12). In the spanwise direction the blocks are $8.5 \mathrm{~m}$ long, on the -streamwise- plane of symmetry of which, the explosive charge and a gauge are located similarly to the configuration presented in sub-section (2.3). The gauge is placed at blocks mid-distance and $0.3 \mathrm{~m}$ above the ground.

Figure (13) shows the overpressure history at the mid-gap-gauge depicted in Figure (12) for the different simulated layouts. Also, Table 10 summarizes the maximum peak of the overpressure, the positive phase impulse and the positive phase duration at that gauge for the different simulated layouts. 


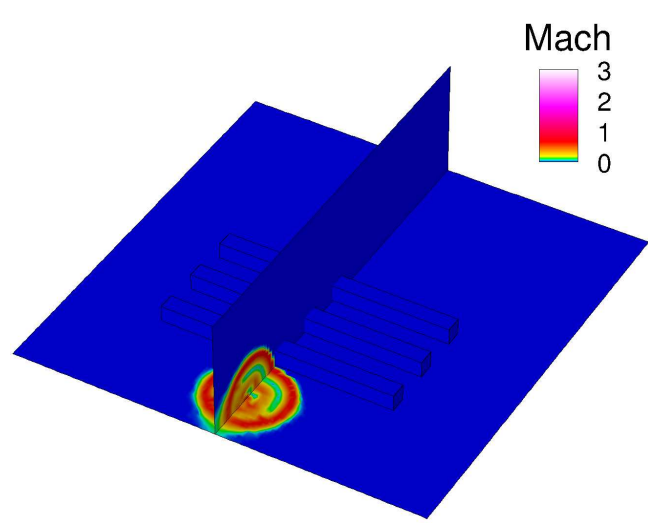

(a) $t=1 \mathrm{~ms}$

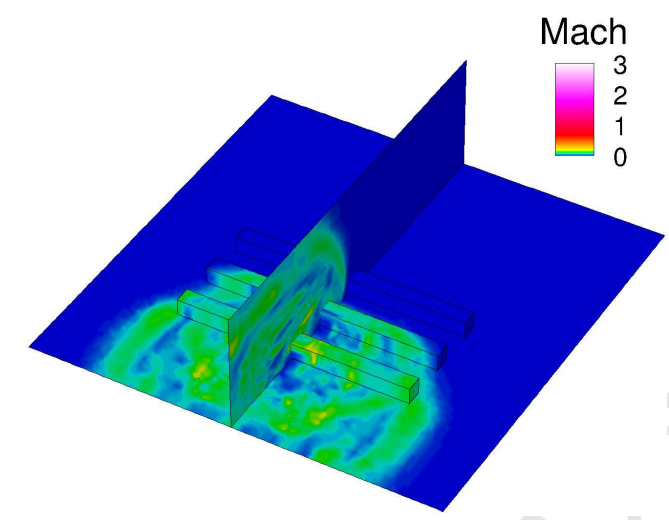

(c) $t=10 \mathrm{~ms}$

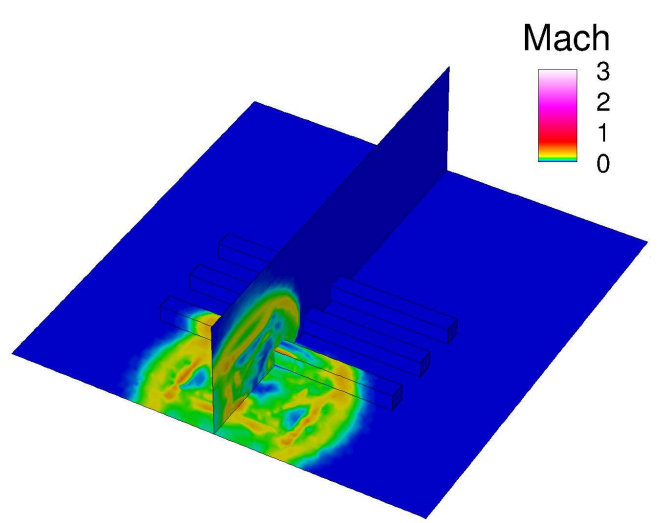

(b) $t=5 \mathrm{~ms}$

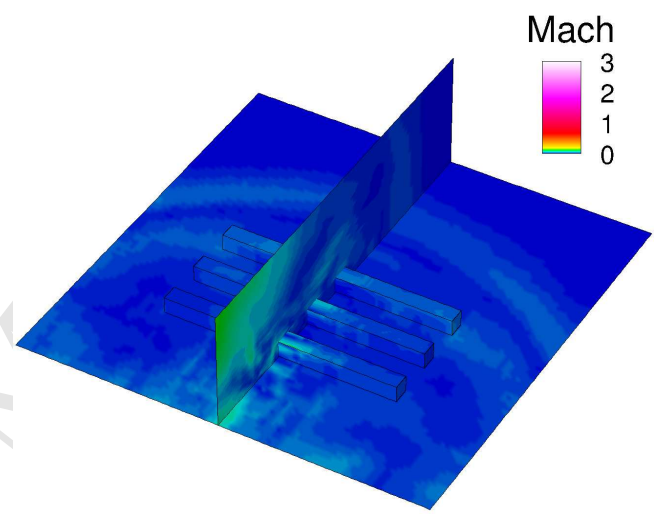

(d) $t=25 \mathrm{~ms}$

Figure 10: Mach number distribution on the ground and on the solid obstacles, from $1 \mathrm{~ms}$ after the detonation to $25 \mathrm{~ms}$.

Clearly the higher the obstacle-height-to-gap-width ratio, $\frac{h}{d}$, the lower the maximum overpressure and impulse, at constant obstacle-width-to-gap-width ratio, $\frac{l}{d}$. Moreover, the higher $\frac{l}{d}$, the higher the maximum overpressure and impulse, at constant $\frac{h}{d}$. The parameter $\frac{l}{d}$ seems to play an impulse concentrative role since -by increasing- the overpressure peak is increased and, at the same time, the phase duration is reduced. Even though delayed, the shape of the pressure signature is fairly the same as $\frac{l}{d}$ varies at constant $\frac{h}{d}$. In other words, when brought to the same arrival time, $\frac{l}{d}$ plays the role of an amplitude modulator parameter of the pressure signal. 


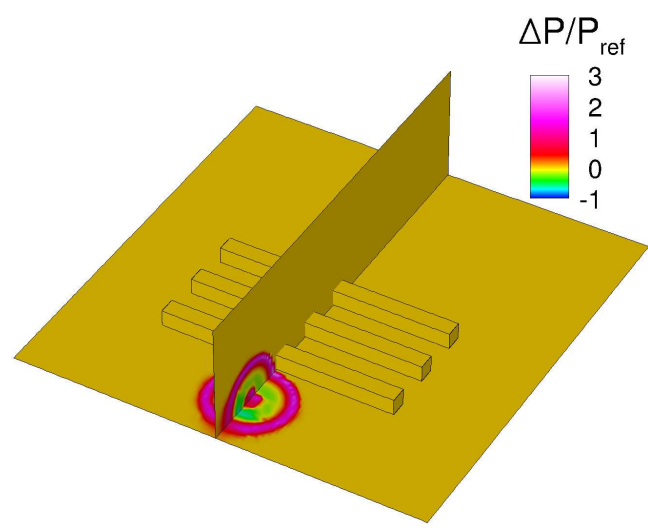

(a) $t=1 \mathrm{~ms}$

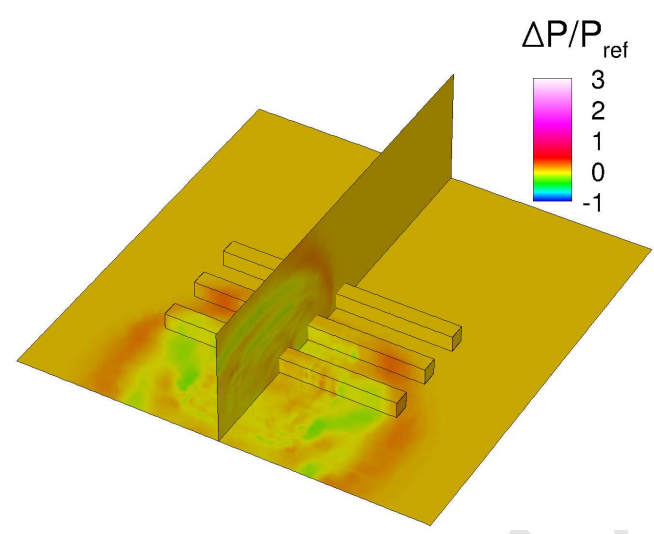

(c) $t=10 \mathrm{~ms}$

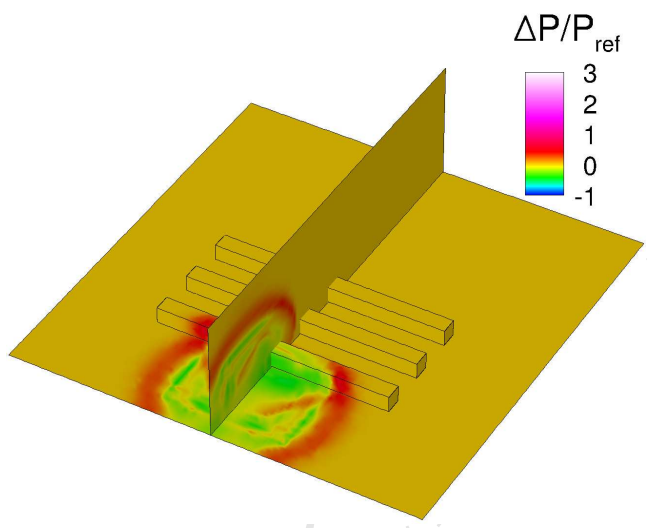

(b) $t=5 \mathrm{~ms}$

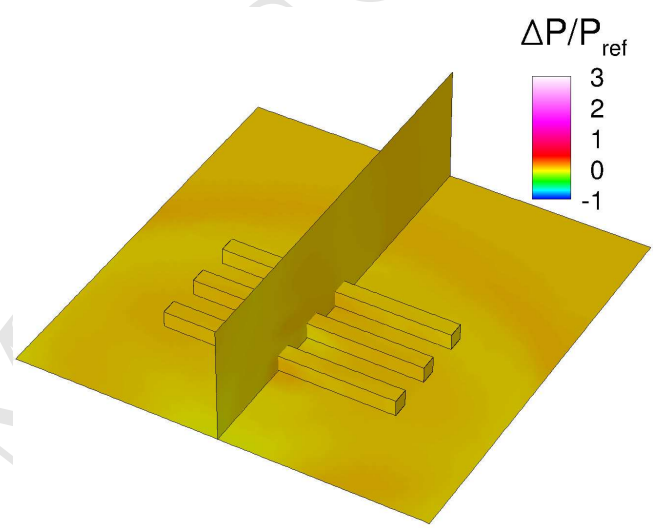

(d) $t=25 \mathrm{~ms}$

Figure 11: Overpressure distribution on the ground and on the solid obstacles, from $1 \mathrm{~ms}$ after the detonation to $25 \mathrm{~ms}$.

The potential for damage to the ground and the structures in each configuration is deduced from SDOF iso-damage model and shown in Figure (14). The constants involved in this model were set as follows: $K=10^{8} \mathrm{~N} / \mathrm{m}^{3}$, $R_{0}=10^{2} \mathrm{~N} / \mathrm{m}^{2}$ and $M=1 \mathrm{~kg} / \mathrm{m}^{2}$. To better distinguish the damage factor variations, the $\alpha^{-1}$ distribution is represented in Figure (14) instead of the $\alpha$ distribution. Consequently, the more critical the damage, the higher the value of $\alpha^{-1}$. As expected, the on-the-ground region close to the explosive charge is more affected by the explosion than the farther regions. A circular zone with a radius of about $1 \mathrm{~m}$ and a width of $0.3 \mathrm{~m}$, centered on the explo- 


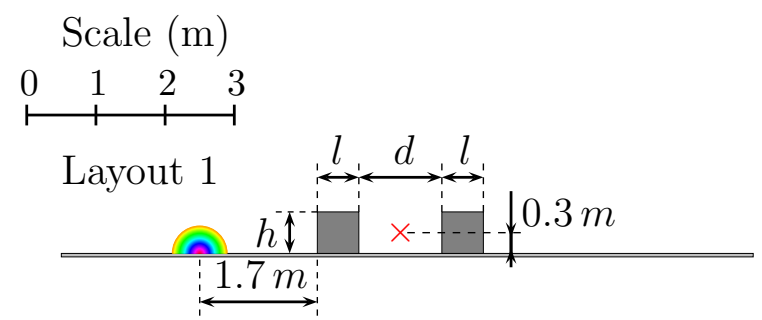

Layout 2

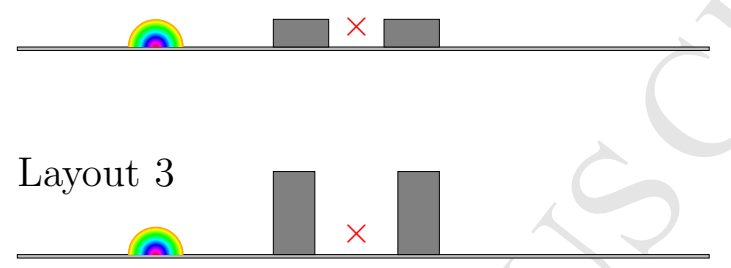

Layout 4
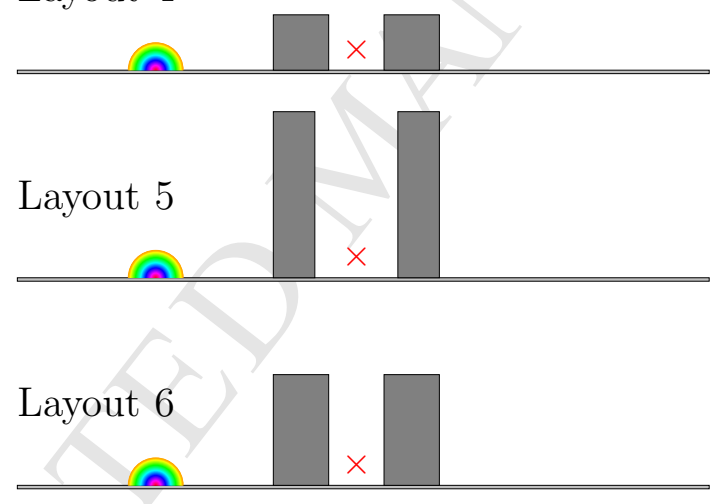

Figure 12: Layouts of the obstacle configurations and the definition of parameters. The symbols $\approx$ and $\times$ represent the explosive charge and the gauge position, respectively.

sive charge, appears to be less blast sensitive than the neighborhood. The offset regions in front of the block facades tend to have a damage potential similar to that of the symmetry plane. Though sustained to high level of damage, the protection provided by the first concrete block is moderately effective. Unlike this latter, the second concrete block appears to have a 
Table 9: Parameters values used in defining the geometric configurations

\begin{tabular}{cccccc}
\hline Layout & $h(m)$ & $l(m)$ & $d(m)$ & $h / d$ & $l / d$ \\
\hline 1 & 0.60 & 0.60 & 1.20 & 0.5 & 0.5 \\
2 & 0.40 & 0.80 & 0.80 & 0.5 & 1 \\
3 & 1.20 & 0.60 & 1.20 & 1 & 0.5 \\
4 & 0.80 & 0.80 & 0.80 & 1 & 1 \\
5 & 2.40 & 0.60 & 1.20 & 2 & 0.5 \\
6 & 1.60 & 0.80 & 0.80 & 2 & 1 \\
\hline
\end{tabular}

Table 10: Maximum overpressure, positive impulse and positive phase duration at the mid-gap gauge

\begin{tabular}{llll}
\hline Layout & $\begin{array}{l}\text { Maximum over- } \\
\text { pressure }(\mathrm{kPa})\end{array}$ & $\begin{array}{l}\text { Positive impulse } \\
(\mathrm{Pas})\end{array}$ & $\begin{array}{l}\text { Positive } \\
\text { duration }(\mathrm{ms})\end{array}$ \\
\hline 1 & 19.75 & 43.13 & 4.65 \\
2 & 28.17 & 50.21 & 3.72 \\
3 & 12.34 & 35.10 & 5.68 \\
4 & 20.74 & 44.49 & 5.36 \\
5 & 7.17 & 26.67 & 7.79 \\
6 & 8.08 & 26.83 & 5.59 \\
\hline
\end{tabular}

considerable blast sheltering effect. Behind the second concrete block, the damage level decays monotonously as the distance from the blast center increases.

In other respects, at constant $\frac{l}{d}$, the higher the value of $\frac{h}{d}$, the more the damage of the first obstacle front facade. At constant $\frac{h}{d}$, the sheltering effect seems to be practically insensitive to $\frac{l}{d}$ variations, although as the value of $\frac{l}{d}$ increases the first obstacle front facade and the blast nearest region seem more likely to sustain damage. In this regard, higher obstacles are more protective than larger ones, at equal gap distance.

\section{Conclusion}

A numerical method for simulating the blast wave propagation in complex geometries was developed in order to accurately predict the structural damage from a high-powered explosive detonation. To show the effectiveness 
of the method, an on-the-ground PE4 explosion (i.e., a TNT equivalent explosion) and the subsequent blast wave were simulated on a congested site represented by series of concrete obstacles. The numerical modeling was successfully validated through comparison with experimental data. The wave signature at different positions was very accurately predicted, notably the integral quantities. The method presented in this paper has shown by this its capability to perform, on standard capacity computers, accurate blast wave simulations at fairly acceptable cost.

The overpressure and Mach number distribution in such complex congested sites reveals wave reflections and diffractions on and over the ground, as well as on and over the obstacles. The single-degree-of-freedom method was used to create the iso-damage diagrams corresponding to different site layouts. These diagrams showed that the offset regions tend to be damaged as much as the zones within the symmetry plane. The sheltering effect becomes noticeable only behind the second obstacle. Away from the obstacles, the damage level decreases smoothly with the increasing distance from the blast center. In addition, the sheltering parametric study of the different site layouts showed that the protection effect is more effective by increasing the obstacle-height-to-gap-width ratio than by modifying the obstacle-width-togap-width ratio. This may be a valuable result to be considered in both preventing or analyzing buildings damage provoked by blast wave.

Although the method presented in this paper may insure real progress in the field of explosion assessment and analysis by providing a very accurate numerical method with a high level of confidence, further developments are nonetheless necessary in order to reduce the computation cost even more by integrating dynamic adaptive mesh methods.

\section{Acknowledgments}

This research was conducted as part of the EGSISTES project supported by the French National Research Agency (ANR) under contrat R287. The authors greatly appreciate the help of D. Uystepruyst in the enhancement of the software developed.

\section{Bibliography}

[1] H. L. Brode. Blast waves from a spherical charge. The Physics of Fluids, 2(2):217-229, 1959. 
[2] B. Vanderstraeten, M. Lefebvre, and J. Berghmans. A simple blast wave model for bursting spheres based on numerical simulation. Journal of Hazardous Materials, 46:145-157, 1996.

[3] W. E. Baker, P. A. Cox, P. S. Westine, J. J. Kulesz, and R. A. Strehlow. Explosion hazards and evaluation. Fundamental studies in engineering. Elsevier, New-York, 1983.

[4] X. Q. Zhou and H. Hao. Prediction of airblast loads on structures behind a protective barrier. International Journal of Impact Engineering, 35:363-375, 2008.

[5] T. C. Chapman, T. A. Rose, and P. D. Smith. Blast wave simulation using AUTODYN2D: a parametric study. International Journal of Impact Engineering, 16:777-787, 1995.

[6] D. Ambrosini, B. Luccionia, A. Jacintoa, and R. Danesia. Location and mass of explosive from structural damage. Engineering structures, 27:167-176, 2005.

[7] S. Sklavounos and F. Rigas. Computer simulation of shock waves transmission in obstructed terrains. Journal of Loss Presention in the process intrustries, 17:407-417, 2004.

[8] A. M. Benselama, M. J.-P. William-Louis, and F. Monnoyer. An efficient numerical method for the onset of blast waves generated by spherical detonation. In International Conference on Mathematical \& Computational Methods in Science, Bucharest, Romania, 2008.

[9] G. W. Ma, H. J. Shi, and D. W. Shu. P-I diagram method for combined failure modes of rigid-plastic beams. International Journal of Impact Engineering, 34:1081-1094, 2006.

[10] Q. M. Li and H. Meng. Pulse loading shape effects on pressure-impulse diagram of an elastic-plastic, single-degree-of-freedom structural model. International Journal of Mechanical Sciences, 44:1985-1998, 2002.

[11] C. K. Youngdahl. Influence of pulse shape on the final plastic deformation of a circular plate. International Journal of Solids Structures, 7:1127-1142, 1971. 
[12] C. Catlin, M. Ivings, S. Myatt, D. Ingram, D. Causon, and L. Qian. Explosion hazard assessment: a study of the feasibility and benifits of extending current HSE methodology to take account of blast sheltering. Technical Report HSL/2001/04, Sheffied Health and Safety Laboratory, 2001.

[13] F. Waymel, F. Monnoyer, and M. J.-P. William-Louis. Numerical simulation of the unsteady three-dimensional flow in confined domains crossed by moving bodies. Computers and fluids, 35:525-543, 2005.

[14] B. van Leer. Towards the ultimate conservative scheme, V. A secondorder sequel to Godunov's method. Journal of Computational Physics, 32(1):101-136, 1979.

[15] F. Deister, E.H. Waymel, F. Hirschel, and F. Monnoyer. Self-organizing hybrid cartesian grid generation and application to external and internal flows. Numerical flow simulation III. In: Hirschel EH, editor. Notes on Numerical Fluid Mechanics and Multidisciplinary Design, 82:18-29, 2002 .

[16] H. L. Brode. Numerical solutions of spherical blast waves. Journal of Applied Physics, 26:766-775, 1955.

[17] A. M. Benselama, M. J.-P. William-Louis, and F. Monnoyer. Étude de sensibilité d'une méthode d'interfaçage 1D-3D numérique. In Congrès Français de Mécanique, Marseille, France, 2009. 


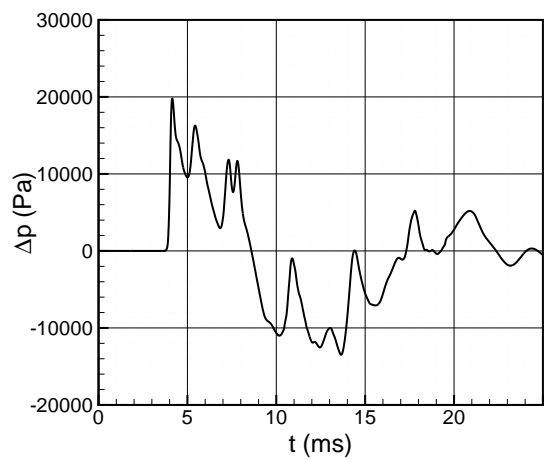

(a) Layout 1: $\frac{h}{d}=0.5, \frac{l}{d}=0.5$

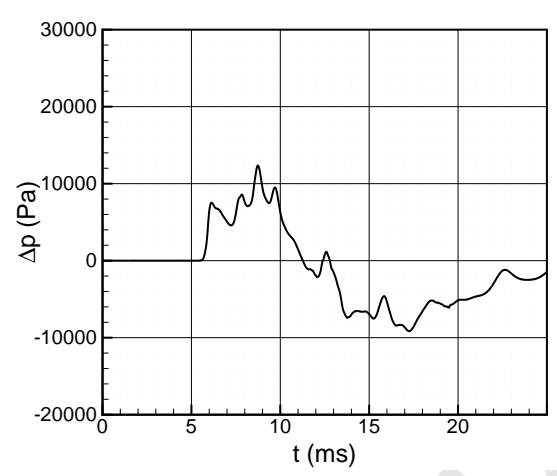

(c) Layout 3: $\frac{h}{d}=1, \frac{l}{d}=0.5$

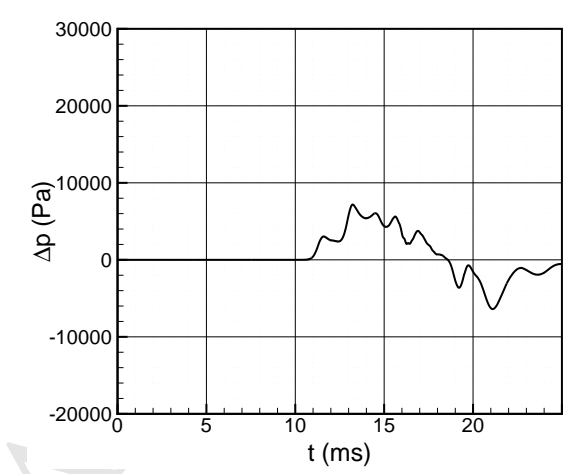

(e) Layout 5: $\frac{h}{d}=2, \frac{l}{d}=0.5$

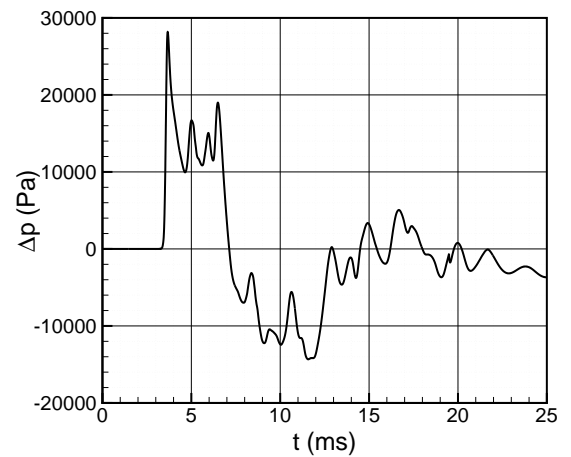

(b) Layout 2: $\frac{h}{d}=0.5, \frac{l}{d}=1$

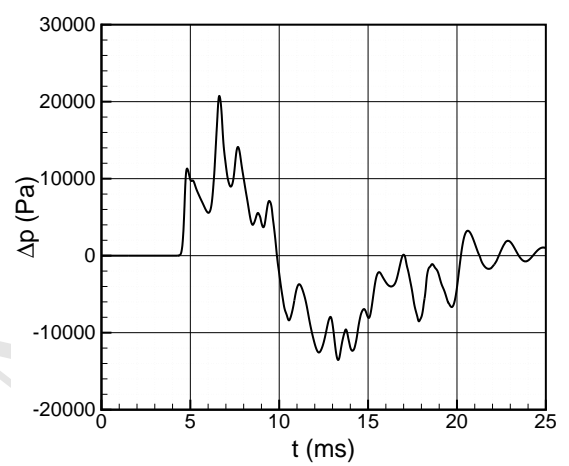

(d) Layout 4: $\frac{h}{d}=1, \frac{l}{d}=1$

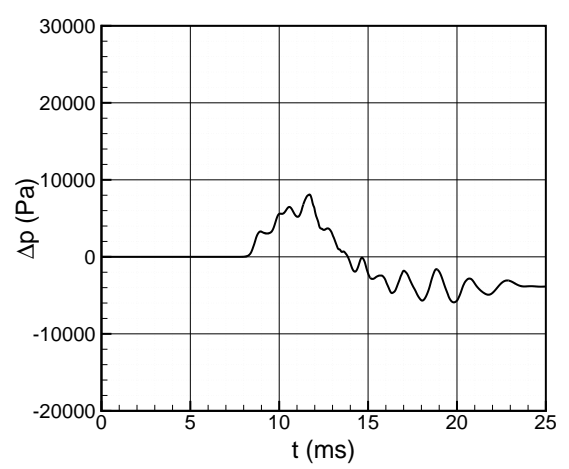

(f) Layout 6: $\frac{h}{d}=2, \frac{l}{d}=1$

Figure 13: Overpressure time history at mid-gap gauge for the various obstacle layouts. 

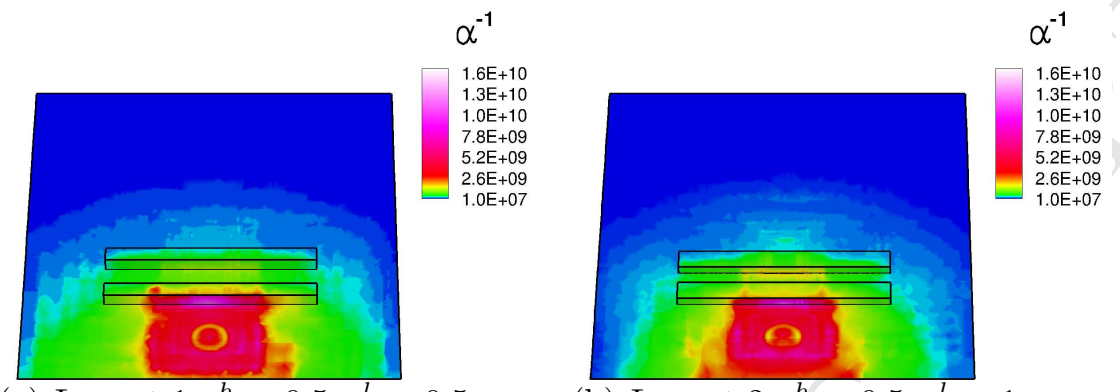

(a) Layout 1: $\frac{h}{d}=0.5, \frac{l}{d}=0.5$

(b) Layout 2: $\frac{h}{d}=0.5, \frac{l}{d}=1$

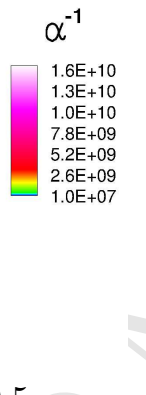

(c) Layout 3: $\frac{h}{d}=1, \frac{l}{d}=0.5$

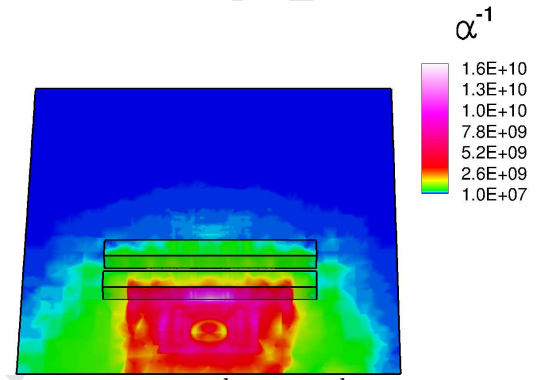

(d) Layout 4: $\frac{h}{d}=1, \frac{l}{d}=1$
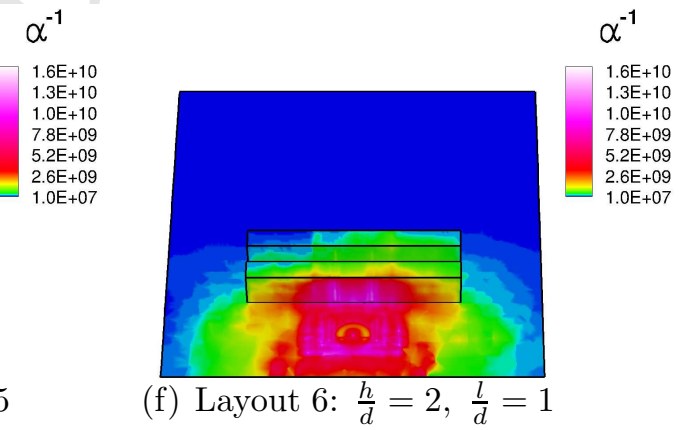

Figure 14: P-I iso-damage diagrams at the various obstacle layouts. 